\title{
Profile of oral health students over a ten year period and their practice intentions after graduation
}

\author{
Suzanne Gardner*1, and Kaye Roberts-Thomson ${ }^{2}$ \\ ${ }^{1}$ Lecturer, Adelaide Dental School, University of Adelaide, South Australia, Australia \\ ${ }^{2}$ Adjunct Professor, Australian Research Centre for Population Oral Health (ARCPOH), Adelaide Dental School, University of Adelaide, South Australia, Australia
}

\begin{abstract}
Objective: Limited research has been published on oral health therapists, particularly Australian cohorts of Bachelor of Oral Health (BOH) students who will graduate as oral health therapists. Aside from selection criteria and sample characteristics of students from some institutions, little is known about factors influencing career choice and career aspirations and workplace intentions after graduation. This study describes the characteristics, career choice factors and career aspirations of first year students enrolled at the University of Adelaide between 2005 and 2014.
\end{abstract}

Methods: All first year cohorts (2005-2014) completed a self-report questionnaire as part of coursework. Demographic data, socio-economic status, career choice influences and graduate aspirations were collected and analysed. Kruskal -Wallis Tests were conducted on each variable with the cohort years.

Results: Completed questionnaires suitable for analyses were received from 269 students (response rate $86 \%$ ). Most students were under 21 years, in their preferred program and attended non-government schools. Males entering the profession increased. Career choice factors reflected those of other studies. The desire to work in the public sector declined after the first year of graduation with most reporting the private sector the workplace of choice after five and ten years. The stated intention of pursuing an academic career did not change and most reported the possibility of undertaking future postgraduate study.

Conclusion: Working conditions and lifestyle factors have become increasing important and a growing number of males are entering the profession. Monitoring profile variations between $\mathrm{BOH}$ student cohorts overtime is important for program selection, recruitment and labourforce planning. If the trend continues for $\mathrm{BOH}$ students wanting to ultimately work in the private sector, access to care could be affected for particular population groups.

\section{Introduction}

The Bachelor of Oral Health program $(\mathrm{BOH})$ commenced at the University of Adelaide in 2002. The degree was formed from the combination of the former Diploma in Dental Therapy and the Advanced Diploma of Dental Hygiene and graduates from this program are known as oral health therapists (OHTs). There has been limited research published about the profile of Australian OHT students since the inception of OHT programs. Selection criteria and sample characteristics of $\mathrm{BOH}$ students at the University of Adelaide [1], the profiles of Newcastle undergraduates [2], and sociodemographic detail and career decisions of Australian and New Zealand $\mathrm{BOH}$ students $[3,4]$ have recently been reported. Marino et al. [4] reported a growing number of males entering the profession, a greater proportion with a dental assisting background and a greater proportion being self-directed in their career motivation 'to care for and help other people'. Other information is gathering about the profession such as the acceptance and utilisation of OHTs in the workforce [5-7] flexible delivery of care [8], employment pathways and work preparedness [9]. It has been suggested that underutilisation of the full scope of practice by OHTs may relate to lack of knowledge by the community and the wider dental profession [3] and that the skill sets they apply are those necessary to meet the demands of the settings in which they practice, and the supervision agreement associated with their conditions of employment [6]. It has also been reported that the attitude of dentists towards auxiliaries has a positive effect on patients' acceptance [10]. The NZ study found that graduates desired more clinical and placement experience prior to graduation and felt that dentistry students should be better informed about the scope of practice of $\mathrm{BOH}$ graduates [9]. Having autonomy in the workplace with fewer restrictions on the provision of clinical services, and a greater understanding by dentists of their capabilities, have been associated with higher levels of satisfaction amongst dental therapists $[11,12]$. Increasing the understanding of career motivation and career aspirations of this group of professionals will assist in informing planners about workforce recruitment and retention; the marketing of the program; and informing curricula in how best to equip students to make meaningful and satisfying workplace choices as graduates. For these reasons, it is timely to build on what is already known about the profile of students in this growing profession $[6,13]$, their future career aspirations, and to observe any trends that may have been apparent over a ten year period. This study reports on the demographic profile of 10 cohorts of first year $\mathrm{BOH}$ students enrolled at the University of Adelaide, influencing factors associated with their career decision and their stated practice intentions after graduation.

Correspondence to: Suzanne Gardner, School of Dentistry, University of Adelaide, South Australia, Australia, Tel: +61 8 83133053, Fax +61 8 8133444; E-mail: sue.gardner@adelaide.edu.au

Key words: career choice, dental students, oral health, workplace preference

Received: December 28, 2016; Accepted: January 23, 2017; Published: January 26,2017 


\section{Methods}

\section{Sample}

A self-report questionnaire was completed by first year $\mathrm{BOH}$ students as part of Professional Studies coursework. Ten cohorts of BOH students (2005 to 2014) were included in the study.

\section{Questionnaire}

The questionnaires were administered and coordinated by dental school staff toward the end of the first semester for each cohort. The survey comprised thirty-two questions. It included sociodemographic detail such as age, sex, country of birth, schooling, family's academic background and occupation, tertiary career preferences and perceived workplaces after graduation. The variables were based on those included in previous studies of dentists and $\mathrm{BOH}$ student's career choices over a long period [4,14-17]. School type variables relating to where students completed their secondary schooling were; South Australian, Other Australian, or overseas State school; and South Australian, Other Australian and Overseas Private School. Location of school options included the eight Australian states and territories, and Overseas. Family level of education was whether their father, mother or siblings had university degrees.

Motivation towards career choice was captured by a choice of ten statements which were; 'your desire to help people', 'the status of dentistry', 'anticipated income', 'good working hours', 'security of the job', 'opportunity to be self-employed', 'work would be interesting', 'work fits in with family commitments', 'work is important', and 'the pleasant working surroundings'. The respondents could answer 'Yes' or 'No' to more than one statement.

Respondents were also asked to indicate who influenced their decision to choose oral health as a career. The nine options given were 'father', 'mother', 'another relative', 'family friend', 'dentist', 'another dental employee', 'career counsellor', 'teacher at school', and 'school friends'.

Workplace intentions were collected by asking students where they were likely to be working one, five and ten years after graduating. Their options were 'Academic dentistry', 'Dental research', 'School Dental Service', 'Defence forces', 'Dental hospital or Public clinic', 'Private practice.'

Other data collected related to age, sex, country of birth, school type and location, tertiary preference, parents' occupation, family's level of education, and postgraduate study intentions.

\section{Data analysis}

Incomplete questionnaires were removed for the analyses. Statistical Package for the Social Sciences (SPSS 23) was used to analyse and manage the data. The data were cleaned and missing values identified.

Age was dichotomized into less than 21 years and 21 years or more to allow for comparisons with previous research [18]. Country of birth was dichotomised into 'Australia' and 'overseas'.

In reference to the location of the secondary school attended the variable dichotomised into 'South Australia' and 'Other', and the type of school attended was regrouped into two categories; attending either a 'State' school (or public) or a 'Private, Independent or Catholic' school.

First tertiary preference was grouped as 'BOH', 'BDS' (Bachelor of Dental Surgery) and 'Other'. The family level of education was determined by whether either parent or sibling was a university graduate. Parents' occupations were reclassified into three groups. The first, 'Upper white collar' included professional and paraprofessional occupations, managers and/or administrators; the second category, 'Lower White Collar' grouped occupations such as tradespersons and related workers, intermediate and advanced clerical, service production and intermediate transport workers; and the third, 'Blue Collar' included unskilled labourers and related workers, and elementary clerical sales and service workers [19].

Postgraduate studies, for the analyses in this report, included an honours degree in addition to masters and doctorates as this is how it was explained and subsequently promoted to the $\mathrm{BOH}$ students. The timing of when students decided on a career in oral health was categorised into four; 'during their matriculation year', 'before their matriculation year, 'after tertiary study' and 'after working or having a post matriculation break'. Future career aspirations variables grouped into three categories Academic/research, Public (School Dental Service/ Hospital/Defence) and Private. Study intentions were collapsed into three groupings, 'Yes/probably', 'possibly' and 'no'.

Frequencies of the variables age, sex, year of entry, country of birth, educational background, parents occupation and education background and career intentions the first, fifth, tenth year after graduation were calculated for each year level. Additionally, frequency distributions for the variables relating to the students motivation and influencing factors in their decision to choose oral health as a career were calculated. 'Father' and 'Mother' were combined and relabelled 'Parent' for the analysis referring to one or both as having an influence over career choice.

Kruskal-Wallis tests were performed on each variable, with the cohort year as the independent variable, to assess the strength of variation over time. A five per cent level of significance was used for all tests.

\section{Ethical considerations}

The study was conducted and complied with the Human Research Ethics Committee (HREC) standards of the University of Adelaide. The research was deemed negligible risk, data was de-identified and entry carried out by an independent research officer.

\section{Results}

\section{Response rate}

Comparable data sets were collected from first-year $\mathrm{BOH}$ undergraduate students from 2005 to 2014 inclusive. Completed questionnaires were received from 271 students out of a possible 317 which was a response rate of $86 \%$. The response rate ranged from $66 \%$ in 2008 to $100 \%$ in 2010 .

\section{Sample characteristics}

Sample characteristics of the cohorts are presented in Table 1. Over half of the students were under 21 years of age (57.2\%). The cohorts between 2007 and 2013 were predominately younger than 21 years $(\mathrm{p}<0.01)$. In 2005 , less than a third were in the younger age group (30.3\%), while in 2009 and 2012, 80\% were younger than 21 years of age. Overall, the mean age of respondents was $21.3(\mathrm{SD}=4.1)$.

Most students were female (85.5\%) and overall, sex was significantly associated with year of cohorts $\left(\chi^{2}(9)=19.76, p<0.05\right)$. Cohorts in 2011 
Table 1. Percentage characteristics of ten cohorts of first year oral health students.

\begin{tabular}{|c|c|c|c|c|c|c|c|c|c|c|c|}
\hline Year of enrolment & 2005 & 2006 & 2007 & 2008 & 2009 & 2010 & 2011 & 2012 & 2013 & 2014 & Total \\
\hline $\mathbf{n}$ & 33 & 28 & 27 & 19 & 25 & 28 & 29 & 25 & 31 & 24 & 269 \\
\hline Mean Age (SD) & $24.3(5.3)$ & $22.0(4.8)$ & $21.5(4.5)$ & $20.3(3.3)$ & $19.6(3.2)$ & $20.0(3.1)$ & $21.7(4.3)$ & $19.5(1.6)$ & $21.0(3.3)$ & $22.1(3.9)$ & $21.3(4.1)$ \\
\hline \multicolumn{12}{|l|}{ Age** $^{* *}$} \\
\hline$<21 \mathrm{yrs}$ & $10(30.3)$ & $13(46.4)$ & $15(55.6)$ & $12(63.2)$ & $20(80.0)$ & $21(75.0)$ & $16(55.2)$ & $20(80.0)$ & $16(51.6)$ & $11(45.8)$ & $154(57.2)$ \\
\hline $21 \&$ over & $23(69.7)$ & $15(53.6)$ & $12(44.4)$ & $7(36.8)$ & $5(20.0)$ & $7(25.0)$ & $13(44.8)$ & $5(20.0)$ & $15(48.4)$ & $13(54.2)$ & $115(42.8)$ \\
\hline \multicolumn{12}{|l|}{ Sex* } \\
\hline Female & $29(87.9)$ & $19(67.9)$ & $23(85.2)$ & $17(89.5)$ & $17(68.0)$ & $24(85.7)$ & $28(96.6)$ & $22(88.0)$ & $30(96.8)$ & $21(87.5)$ & $230(85.5)$ \\
\hline Male & $4(12.1)$ & $9(32.1)$ & $4(14.8)$ & $2(10.5)$ & $8(32.0)$ & $4(14.3)$ & $1(3.4)$ & $3(12.0)$ & $1(3.2)$ & $3(12.5)$ & $39(14.5)$ \\
\hline \multicolumn{12}{|l|}{ Country of Birth* (267) } \\
\hline Australia & $28(87.9)$ & $27(96.4)$ & $20(74.1)$ & $18(94.7)$ & $21(84.0)$ & $26(96.4)$ & $22(75.9)$ & $25(100.0)$ & $27(87.1)$ & $19(87.3)$ & $233(87.3)$ \\
\hline Other & $4(12.1)$ & $1(3.6)$ & $7(25.9)$ & $1(5.3)$ & $4(16.0)$ & $1(3.6)$ & $7(24.1)$ & $0(0.0)$ & $4(12.9)$ & $5(12.7)$ & $34(12.7)$ \\
\hline \multicolumn{12}{|l|}{ Secondary School Location $(n=267)$} \\
\hline South Australia & $22(68.8)$ & $23(82.1)$ & $23(88.5)$ & $17(89.5)$ & $23(92.0)$ & $25(89.3)$ & $21(72.4)$ & $20(80.0)$ & $26(83.9)$ & $20(83.3)$ & $220(82.4)$ \\
\hline Other & $10(31.3)$ & $5(17.9)$ & $3(11.5)$ & $2(10.5)$ & $2(8.0)$ & $3(10.7)$ & $8(27.6)$ & $5(20.0)$ & $5(16.1)$ & $4(16.7)$ & $47(17.6)$ \\
\hline \multicolumn{12}{|l|}{ Secondary School Type (n=276) } \\
\hline State & $18(56.3)$ & $17(60.7)$ & $14(53.8)$ & $8(42.1)$ & $11(44.0)$ & $12(42.9)$ & $12(41.4)$ & $10(40.0)$ & $10(32.3)$ & $10(41.7)$ & $122(45.7)$ \\
\hline Private/Independent/Catholic & $14(43.8)$ & $11(39.3)$ & $12(46.2)$ & $11(57.9)$ & $14(56.0)$ & $16(57.1)$ & $17(58.6)$ & $15(60.0)$ & $21(67.7)$ & $14(58.3)$ & $145(54.3)$ \\
\hline \multicolumn{12}{|l|}{$1^{\text {st }}$ Tertiary Preference $(n=253)$} \\
\hline Oral Health & $17(58.6)$ & $12(48.0)$ & $13(50.0)$ & $9(56.2)$ & $10(41.7)$ & $11(40.7)$ & $22(75.9)$ & $20(80.0)$ & $19(65.5)$ & $17(73.9)$ & $150(59.3)$ \\
\hline Dentistry & $9(31.0)$ & $11(44.0)$ & $9(34.6)$ & $7(43.8)$ & $11(45.8)$ & $13(48.1)$ & $3(10.3)$ & $4(16.0)$ & $7(24.1)$ & $5(21.7)$ & $79(31.2)$ \\
\hline Other & $3(10.3)$ & $2(8.0)$ & $4(15.4)$ & $0(0.0)$ & $3(12.5)$ & $3(11.1)$ & $4(13.8)$ & $1(4.0)$ & $3(10.3)$ & $1(4.3)$ & $24(9.5)$ \\
\hline \multicolumn{12}{|l|}{ Family Education $(\mathrm{n}=264)$} \\
\hline Father Unigraduate Yes & $10(30.3)$ & $6(21.4)$ & $8(30.8)$ & $5(26.3)$ & $8(32.0)$ & $10(37)$ & $10(34.5)$ & $10(40.0)$ & $10(32.3)$ & $7(30.4)$ & $84(31.6)$ \\
\hline Mother Unigraduate Yes & $6(18.2)$ & $6(21.4$ & $8(29.6)$ & $4(21.1)$ & $7(28.0)$ & $9(32.1)$ & $9(31.0)$ & $11(44.0)$ & $11(35.5)$ & $12(54.5)$ & $83(31.1)$ \\
\hline Sibling Unigraduate Yes & $15(45.5)$ & $9(32.1)$ & $8(30.8)$ & $7(38.9)$ & $10(40.0)$ & $14(50.0)$ & $8(27.6)$ & $7(28.0)$ & $9(29.0)$ & $10(43.5)$ & $97(36.5)$ \\
\hline \multicolumn{12}{|l|}{ Father's Occupation (n=244) } \\
\hline Upper white collar & $20(62.5)$ & $15(57.7)$ & $11(50.0)$ & $11(57.9)$ & $11(55.0)$ & $15(55.6)$ & $14(51.9)$ & $14(56.0)$ & $11(42.3)$ & $12(60.0)$ & $134(54.9)$ \\
\hline Lower white collar & $10(31.3)$ & $9(34.6)$ & $9(40.9)$ & $6(31.6)$ & $6(30.0)$ & $9(33.3)$ & $10(37.0)$ & $10(40.0)$ & $9(34.6)$ & $4(20.0)$ & $82(33.6)$ \\
\hline Blue collar & $2(6.3)$ & $2(7.7)$ & $2(9.1)$ & $2(10.5)$ & $3(15.0)$ & $3(11.1)$ & $3(11.1)$ & $1(4.0)$ & $6(23.1)$ & $4(20.0)$ & $28(11.5)$ \\
\hline \multicolumn{12}{|l|}{ Mother's Occupation (n=231) } \\
\hline Upper white collar & $13(40.6)$ & $12(50.0)$ & $9(40.9)$ & $8(44.4)$ & $10(52.6)$ & $11(52.4)$ & $14(56.0)$ & $14(58.3)$ & $11(39.3)$ & $9(50.0)$ & $111(48.1)$ \\
\hline Lower white collar & $13(40.6)$ & $10(41.7)$ & $12(54.5)$ & $8(44.4)$ & $9(47.4)$ & $5(23.8)$ & $8(32.0)$ & $8(33.3)$ & $7(25.0)$ & $6(33.3)$ & $86(37.2)$ \\
\hline Blue collar & $6(18.8)$ & $2(8.3)$ & $1(4.5)$ & $2(11.1)$ & $0(0 . .0)$ & $5(23.8)$ & $3(12.0)$ & $2(8.3)$ & $10(35.7)$ & $3(16.7)$ & $34(14.7)$ \\
\hline
\end{tabular}

Kruskal-Wallis H Test $* \mathrm{p}<0.05 ; * * \mathrm{p}<0.01 ; \mathrm{SD}=$ Standard Deviation.

and 2013 saw $96 \%$ of females in the respective cohorts. In 2006 and 2009 , around a third (32\%) of the students were male. Enrolees were mostly born in Australia ranging from $74 \%$ in 2007 to $100 \%$ in 2012 which showed a significant result in relation to the cohorts $\left(\chi^{2}(9)=\right.$ 17.91, $\mathrm{p}<0.05)$. Most students attended secondary school in South Australia (82.4\%) which ranged from $68.8 \%$ in 2005 to $92 \%$ in 2009. Over half the students attended a private, independent or catholic school for their secondary education (54.3\%), and the remainder attended a state or public high school (45.7\%). Almost $60 \%$ nominated $\mathrm{BOH}$ as their first tertiary preference; the range was between $41.7 \%$ in 2009 and $80 \%$ in 2012 . Under a third (31.2\%), nominated Dentistry as their first preference. When asked about the education levels of their parents, around a third of the parents were university graduates. Specifically, for fathers, the proportions ranged from $21.4 \%$ in 2006 to $40.0 \%$ in 2012 and for mothers, the range was from $18.2 \%$ in 2005 to $54.5 \%$ in 2014 .

\section{Timing of career decision}

Overall, a third of the students decided to pursue a career in oral health after having a post matriculation break or after working (Table 2). Around half of the earlier cohorts, namely 2005 and 2006, decided to study $\mathrm{BOH}$ after having a break from school. This became less apparent in the most recent cohorts when less than a third made their decision at that time.

\section{Motivating and influencing factors towards career decision}

The two most reported reasons to study $\mathrm{BOH}$ were 'to help people' (92.0\%) and 'interesting job' (91.3\%) followed closely by 'job security' (77.8\%). The least reported reasons were 'status' $(40.9 \%)$ and the opportunity to be 'self-employed' (40.1\%) (Table 3). There was a significant association between year of cohorts and being motivated by the 'job security' $(\mathrm{p}=0.001)$ and the 'important work' $(\mathrm{p}<0.05)$ and the 'opportunity to be self-employed' ( $\mathrm{p}<0.01)$. Just over half $(53.6 \%)$ in 2013 compared with almost all (96\%) in 2010 and 2012 cohorts nominated 'job security' as an important motivator. In 2009, less than half (41.7\%) nominated the 'important work' as a motivator compared with all other cohorts who rated it much higher (ranging from $63.6 \%$ in 2005 to $84 \%$ in 2008 and 2012). 'Opportunity to be self-employed' ranged from $18.2 \%$ for the 2005 cohort to $63.2 \%$ for the 2008 and $60.9 \%$ for the 2014 cohort as a career motivator for $\mathrm{BOH}$. People or persons having the most influence over career decisions were a dentist (47.1\%) or other dental worker (39.1\%) with their school teacher having the least (6.9\%). Friends, relatives and career advisors were all similar in that they had low influence, (ranging between 11 and 18\%), on the students decision to pursue a career in oral health. Dentists and other dental workers played an important role in influencing the $\mathrm{BOH}$ students to choose a career in oral health. There was a significant association between dentists influence and the cohorts $(\mathrm{p}=0.001)$. Nearly three 
Table 2. Percentages of career decision timing of ten cohorts of first year oral health students.

\begin{tabular}{|c|c|c|c|c|c|c|c|c|c|c|c|}
\hline Year of enrolment & 2005 & 2006 & 2007 & 2008 & 2009 & 2010 & 2011 & 2012 & 2013 & 2014 & Total \\
\hline n & 32 & 26 & 26 & 17 & 25 & 28 & 28 & 25 & 31 & 24 & 262 \\
\hline \multicolumn{12}{|l|}{ Decision to study $\mathbf{B O H}^{\text {ns }}$} \\
\hline During matriculation year & 21.2 & 35.7 & 29.6 & 31.6 & 40 & 46.4 & 24.1 & 24 & 16.1 & 16.7 & 28.6 \\
\hline Before matriculation year & 12.1 & 7.1 & 18.5 & 26.3 & 28 & 17.9 & 24.1 & 44 & 25.8 & 25 & 22.3 \\
\hline After tertiary study & 15.2 & 7.1 & 22.2 & 10.5 & 16 & 7.1 & 13.8 & 4 & 29 & 25 & 15.2 \\
\hline After working/post matriculation break & 51.5 & 50 & 29.6 & 31.6 & 12 & 28.5 & 37.9 & 28 & 29.1 & 33.3 & 33.8 \\
\hline
\end{tabular}

ns $=$ Kruskal-Wallis H Test $\mathrm{p}>0.05$.

Table 3. Percentages of career choice motivators and influences of ten cohorts of first year oral health students.

\begin{tabular}{|c|c|c|c|c|c|c|c|c|c|c|c|}
\hline Year of enrolment & 2005 & 2006 & 2007 & 2008 & 2009 & 2010 & 2011 & 2012 & 2013 & 2014 & Total \\
\hline n & 33 & 28 & 27 & 19 & 25 & 28 & 29 & 25 & 31 & 24 & 269 \\
\hline \multicolumn{12}{|l|}{$\dagger$ Motivation } \\
\hline To help people & 90.9 & 96.3 & 92.6 & 94.7 & 83.3 & 82.1 & 100 & 100 & 86.2 & 95.7 & 92 \\
\hline Interesting job & 87.9 & 89.3 & 88.9 & 94.7 & 91.7 & 89.3 & 93.1 & 100 & 86.2 & 95.7 & 91.3 \\
\hline Job security** & 69.7 & 82.1 & 66.7 & 89.5 & 83.3 & 96.4 & 81.5 & 96 & 53.6 & 63.6 & 77.8 \\
\hline Important work* & 63.6 & 71.4 & 81.5 & 84.2 & 41.7 & 75 & 81.5 & 84 & 75 & 78.3 & 73.3 \\
\hline Good work hours & 63.6 & 57.1 & 77.8 & 73.7 & 66.7 & 71.4 & 79.3 & 84 & 75.9 & 69.6 & 71.7 \\
\hline Perceived income & 57.6 & 67.9 & 59.3 & 52.6 & 70.8 & 53.6 & 58.6 & 68 & 42.9 & 54.5 & 58.6 \\
\hline Pleasant surrounds & 54.5 & 57.1 & 66.7 & 52.6 & 52.2 & 46.4 & 71.4 & 60 & 75 & 87 & 62.2 \\
\hline Fits with family & 54.5 & 39.3 & 63 & 52.6 & 33.3 & 32.1 & 50 & 68 & 57.1 & 47.8 & 49.8 \\
\hline Status & 24.2 & 51.9 & 51.9 & 42.1 & 45.8 & 42.9 & 33.3 & 48 & 32.1 & 42.9 & 40.9 \\
\hline Self-employed** & 18.2 & 28.6 & 22.2 & 63.2 & 41.7 & 35.7 & 44.4 & 48 & 53.6 & 60.9 & 40.1 \\
\hline \multicolumn{12}{|l|}{$\dagger$ Influences } \\
\hline Dentist** & 27.3 & 57.1 & 63 & 52.9 & 47.8 & 35.7 & 19.2 & 72 & 43.3 & 62.5 & 47.1 \\
\hline Other dental & 39.4 & 39.3 & 37 & 41.2 & 34.8 & 32.1 & 30.8 & 56 & 40 & 41.7 & 39.1 \\
\hline Parent & 24.2 & 32.1 & 29.6 & 29.4 & 39.1 & 40.7 & 34.6 & 36 & 26.9 & 27.3 & 31.9 \\
\hline Family friend & 12.5 & 3.6 & 14.8 & 11.8 & 21.7 & 28.6 & 30.8 & 28 & 13.3 & 16.7 & 18.1 \\
\hline Relative & 9.1 & 10.7 & 14.8 & 17.6 & 26.1 & 10.7 & 19.2 & 28 & 13.3 & 16.7 & 16.1 \\
\hline School friend & 12.1 & 10.7 & 7.4 & 22.2 & 16.7 & 14.3 & 23.1 & 8 & 6.7 & 4.2 & 12.2 \\
\hline Careers advisor & 12.1 & 7.1 & 7.4 & 29.4 & 13 & 7.1 & 19.2 & 8 & 6.7 & 8.3 & 11.1 \\
\hline Teacher & 6.1 & 10.7 & 3.7 & 23.5 & 4.3 & 3.6 & 7.7 & 4 & 3.3 & 8.3 & 6.9 \\
\hline
\end{tabular}

Kruskal-Wallis H Test $* \mathrm{p}<0.05 ; * * \mathrm{p}<0.01 ; \nmid$ Respondents were able to nominate more than one response

quarters (72\%) of the 2013 cohort were influenced by a dentist but only $19.2 \%$ in 2011 (Table 3). Around a third (31.9\%) was influenced by a parent. In 2009 and 2010 around $40 \%$ nominated a parent as playing an influencing role although this was not significant (Table 3).

The distribution of responses about what type of practice they believe they will be in one, five and ten years after graduation are presented in Table 4 . Over half $(55.6 \%)$ perceived or expected that they be working in the public system on graduation, $\left(\chi^{2}(9)=23.10\right.$, $\mathrm{p}<0.01)$. After five years, this reduced to less than a third $(30.7 \%)$ $\left(\chi^{2}(9)=17.42, p<0.05\right)$, and ten years after graduating, the greater proportion expected to be working in a private practice $(80.3 \%)\left(\chi^{2}\right.$ $(9)=17.48, p<0.05)$. Around four percent indicated that they would prefer an academic career or would be undertaking research first year after graduation. This proportion did not change when asked of their intention at the three time periods. When asked about their intention to do postgraduate studies, around a third responded 'Yes/probably' (33.8\%) and 'Possibly' (38.3\%) and most (61\%) $\left(\chi^{2}(9)=18.22, \mathrm{p}<0.05\right)$, indicated that they would study fulltime.

\section{Discussion_}

This study set out to report the characteristics of the $\mathrm{BOH}$ student cohorts over a ten year period and to report on the first year students' perceptions of their likely workplace in the year after graduation, five years after graduation and ten years after graduation. The study also aimed to capture the likelihood of students participating in postgraduate studies in the future.

Firstly, the mean age (21.3, SD 4.1) of student participants in this survey was similar to previous reports of $\mathrm{BOH}$ students at the same institution [4] however, it was noted that more younger students entered the course after 2005. The proportion of younger students (<21 years) ranged from $30 \%$ in 2005 to $80 \%$ in 2009 and 2012 . This age distribution is in contrast to a wider population of OHT students surveyed from nine different institutions in Australian and New Zealand where the mean age was 23.7 (SD 6.3).

There were slightly more males (14.5\%) entering the $\mathrm{BOH}$ at the University of Adelaide compared to the proportions reported in other $\mathrm{BOH}$ programs combined [4]. Australian dental workforce data collected in 2012, reported $15 \%$ of registered male OHTs [20]. This change from a traditionally female profession appears to be quite rapid. By means of comparison, male nurses for example, made up $10 \%$ of the national average nurses workforce in 2011, although a greater proportion worked in mental health $(33 \%)$ and in areas of developmental disability (28\%) [21]. It is possible that providing oral care to specific disadvantaged groups may be an area suited to male $\mathrm{BOH}$ graduates in the future, and a way of addressing workforce shortages and improving access for disadvantaged groups $[8,22]$. Dental therapists were originally introduced into Australia and New Zealand as a 'low cost auxiliary' to work primarily in the public sector providing restorative and preventive services for children [22]. 
Table 4. Frequencies of students work intentions first, fifth, tenth year after graduation, and study likelihood, by year of enrolment.

\begin{tabular}{|c|c|c|c|c|c|c|c|c|c|c|c|}
\hline Year of enrolment & 2005 & 2006 & 2007 & 2008 & 2009 & 2010 & 2011 & 2012 & 2013 & 2014 & Total \\
\hline n (returned surveys) & 33 & 28 & 27 & 19 & 25 & 28 & 29 & 25 & 31 & 24 & 269 \\
\hline \multicolumn{12}{|c|}{$1^{\text {st }}$ yr after Graduation** } \\
\hline Academic/research & $0(0.0)$ & $0(0.0)$ & $2(7.4)$ & $0(0.0)$ & $5(20.0)$ & $0(0.0)$ & $0(0.0)$ & $0(0.0)$ & $3(9.7)$ & $2(8.3)$ & $12(4.5)$ \\
\hline Public (SDS/Hosp/Defence) & $13(39.4)$ & $16(57.1)$ & $16(59.3)$ & 11(61.1) & $12(48.0)$ & $17(60.7)$ & $17(58.6)$ & $10(40.0)$ & $19(61.3)$ & $18(75.0)$ & $149(55.6)$ \\
\hline Private & $20(60.6)$ & $12(42.9)$ & $9(33.3)$ & $7(38.9)$ & $8(32.0)$ & $11(39.3)$ & $12(41.4)$ & $15(60.0)$ & $9(29.0)$ & $4(16.7)$ & 107(39.9) \\
\hline \multicolumn{12}{|c|}{ 5th yr after Graduation* } \\
\hline Academic/research & $1(3.0)$ & $2(7.1)$ & $1(3.8)$ & $1(5.6)$ & $4(16.7)$ & $2(7.1)$ & $0(0.0)$ & $0(0.0)$ & $0(0.0)$ & $0(0.0)$ & $11(4.2)$ \\
\hline Public (SDS/Hosp/Defence) & $7(21.2)$ & $10(35.7)$ & $13(50.0)$ & $4(22.2)$ & $8(33.3)$ & $6(21.4)$ & $5(17.2)$ & $6(24.0)$ & $14(46.6)$ & $8(34.8)$ & $81(30.7)$ \\
\hline Private & $25(75.8)$ & $16(57.1)$ & $12(46.2)$ & $13(72.2)$ & $12(50.0)$ & $20(71.4)$ & $24(82.8)$ & $19(76.0)$ & $16(53.3)$ & $15(65.2)$ & $172(65.2)$ \\
\hline \multicolumn{12}{|c|}{ 10th yr after Graduation* } \\
\hline Academic/research & $3(9.1)$ & $1(3.6)$ & $1(3.8)$ & $1(5.6)$ & $2(8.3)$ & $0(0.0)$ & $0(0.0)$ & $1(4.0)$ & $3(10.0)$ & $0(0.0)$ & $12(4.5)$ \\
\hline Public (SDS/Hosp/Defence) & $3(9.1)$ & $3(10.8)$ & $5(19.2)$ & $1(5.6)$ & $5(20.9)$ & $3(10.7)$ & $3(10.3)$ & $2(8.0)$ & $10(33.3)$ & $5(21.7)$ & $40(15.2)$ \\
\hline Private & $27(81.8)$ & $24(85.7)$ & $20(76.9)$ & $16(88.9)$ & $17(70.8)$ & $25(89.3)$ & $26(89.7)$ & $22(88.0)$ & $17(56.7)$ & $18(78.3)$ & $212(80.3)$ \\
\hline \multicolumn{12}{|c|}{ Intend to do PG Studies } \\
\hline Yes/probably & $12(36.4)$ & $11(39.3)$ & $11(40.7)$ & $4(21.1)$ & $11(44.0)$ & $7(25.0)$ & $10(34.5)$ & $7(28.0)$ & $12(38.7)$ & $6(25.0)$ & $91(33.8)$ \\
\hline Possibly & $7(21.2)$ & $12(42.9)$ & $10(37.0)$ & $13(68.4)$ & $11(44.0)$ & $12(42.9)$ & $9(31.0)$ & $10(40.0)$ & $9(29.0)$ & $10(41.7)$ & 103(38.3) \\
\hline No & $14(42.4)$ & $5(17.9)$ & $6(22.2)$ & $2(10.5)$ & $3(12.0)$ & $9(32.1)$ & $10(34.5)$ & $8(32.0)$ & $10(32.3)$ & $8(33.3)$ & $75(27.9)$ \\
\hline \multicolumn{12}{|c|}{$\dagger$ Would study full time* } \\
\hline Yes & $9(42.9)$ & $14(58.3)$ & $14(66.7)$ & $6(37.5)$ & $17(73.9)$ & $13(65.0)$ & $13(65.0)$ & $11(61.1)$ & $20(76.9)$ & $9(52.9)$ & $126(61.2)$ \\
\hline No & $12(57.1)$ & $10(41.7)$ & $7(33.3)$ & $10(62.5)$ & $6(26.1)$ & $7(35.0)$ & $7(35.0)$ & $7(38.9)$ & $6(23.1)$ & $8(47.1)$ & $80(38.8)$ \\
\hline
\end{tabular}

Kruskal-Wallis H Test ${ }^{*} \mathrm{p}<0.05 ;{ }^{*} \mathrm{p}<0.01$; †Only those who indicated they would study are included in 'would you study full time' variable.

Note: Not all columns add up to $100 \%$ due to rounding up.

Country of birth was reported as Australia for most participants (87\%). The remainder were from 19 countries in the following regions; the Middle East, South East Asia, Europe, South America and New Zealand. Marino et al. [4] broader study of $\mathrm{BOH}$ students showed a greater diversity of students' ethnicities. In this study, there was significant variation between Australian born students and cohort years for reasons that are not clearly evident.

Less than half the students attended public schools in this Adelaide study compared with over two thirds (69.2\%) in the wider comparison of $\mathrm{BOH}$ students [4] which may indicate a tendency that students are from privileged backgrounds as has been reported for dental students at the same institution $[17,23]$. It may be that this institution is more attractive to students from privileged backgrounds irrespective of the programs it offers. Although not presented, the majority of fathers (54\%) where in professional, technical or related employment and most mothers (48\%) were in similar employment, thus reaffirming that students in this study were from higher SES backgrounds [21]

The fact that many students indicated that $\mathrm{BOH}$ was not their first preference could be interpreted in difference ways. Potentially, being in a non-preferred course could affect student performance, although other studies have indicated to the contrary $[1,24]$. It is not unusual for students to miss out on being offered a place in their preferred course or program of study because of limited places available and competitive selection criteria. Dental students, for example, have often place medicine as their preferred career option $[1,16]$.

Most students in this study decided on a career in oral health once they had left school. This could be explained by many having a background in dental assisting as did a significant proportion of $\mathrm{BOH}$ graduates in a recent study [4]. Twelve percent also had undertaken other tertiary study. Fewer students had made their decision during or before their matriculation break. This reinforces the very little impact that school teachers and career counsellors have in students' career decision making in this Adelaide survey; similar to the results reported by others $[1,4,15,25]$ and similarly, applicable for dental students $[15,17]$. The overall minimal impact could be that counsellors themselves lacked accurate information about the profession, or that relevant program material had not been made available to school students.

When investigating the preferred career preference from students from other health professions, (e.g., medicine, nursing, other allied health), Schofield and colleagues found that preference for practice location depended on ethnicity, age, sex, and discipline amongst other things [26]. In this current study, $12 \%$ of students were born outside Australia which was much less than the proportion reported by dental students at the University of Adelaide (38\% between 1997-2005) [17]. Although not reported, $16.9 \%$ of students in this study spoke a language other than English which is close to the 18\% reported in the 2011 census [27]. This suggests that for $\mathrm{BOH}$ students, any preference of practice location or workplace preference based on ethnicity, could be negated.

The results of this survey indicate a strong shift in emphasis from previous studies where the opportunity to be self-employed as a main motivator has been overshadowed by working conditions such as flexibility of hours, job security and family or lifestyle related factors. This trend toward lifestyle and income as motivating factors has also become increasingly important of late to medical students' career choice [28-30] therefore it was not surprising to see it reflected in this study of $\mathrm{BOH}$ students.

Further research is necessary to track the differences between first year students stated intentions and how these may alter over the course of the program and after graduation. This study revealed that four out of five first year students had the intention of working in private practice 10 years after graduation. The proportion doubled from only two in ten students indicating their intention to work in private practice one year after graduation. It would be interesting to explore the reason for this shift in preference. Primary concerns raised by stakeholders in relation to the OHT workforce were funding restraints (hence most employed in the private sector) and lack of clarity associated with scope of practice (potentially a reason for practitioners not hiring OHTs) [13]. 
It could be that students perceive government or public sector practice to be a 'safe' option in the first instance, or it may reflect that remuneration is greater once practitioners become more established in their careers and hence the preference toward private practice after ten years. In 2012, 364(55\%) of employed registered OHTs were working in private practice, $11(1.6 \%)$ were employed as teachers/educators and $5(0.7 \%)$ were primarily engaged in research [20]. A considerable proportion of OHTs work in two and three or more locations $(29.3 \%$ and $9.8 \%$ respectively) compared with around five percent of the wider workforce working in multiple locations [6]. A recent NZ study reported that graduates had a desire for clinical variety, where they were able to use their full range of scope of practice skills, and that this opportunity was less likely to occur in the public sector or in 'not for profit' positions in oral health [9]. The less than one percent engaged in research appears to be a very small proportion of the OHT workforce despite $72 \%$ in this study indicating that they would 'probably' or 'possibly' undertake postgraduate studies when asked as first year students. Perhaps $\mathrm{BOH}$ students are not thinking of a traditional research career but rather the traditional practitioner's role of seeking 'viable' employment as has been reported in other studies [31,32]. It is possible too, that career aspirations may be associated with the generation of students in this study.

Most of the students in this study were representative of the Generation Y's, or Millennials, as they are sometimes known (born 1982-2000) [33]. Not a lot is understood about the career aspirations of Generation Y's other than they are generally accepting of authority, well watched over, have a fascination with new technology, likely to set high standards, and will 'focus on the needs of the community more than the individual' [33]. They have been described as 'self-confident, goaloriented, well-socialized, compliant and drawn to collective action' and place emphasis on family and friends first when it comes to choices and are very often driven by independence, stability and loyalty [34]. Generation Y's in this study rated helping people, the importance of the work, and job security as being of high importance which is consistent with previous findings of this generation of students [4]. Generation X'ers by comparison (born 1963-1981), are typically characterized as individualists, comfortable with change, more independent and selfsufficient than previous generations, and who are likely to seek out more than one job and open to more challenging employment options offering higher salaries or improved benefits. This could explain why income and status did not rate high as important motivators for the students in this study.

\section{Implication for practice}

Having a better understanding of the intentions of $\mathrm{BOH}$ graduates career plans immediately following graduation may better inform those responsible for workforce planning and projections [9]. The $\mathrm{BOH}$ is a relatively new program and it is important that undergraduates are supported in their preparedness for career opportunities, not only in their clinical settings, but also for those wanting academic careers in teaching and/or research. Building a greater body of evidence around oral health practitioners and their career intentions supports growth in research, education, and practice [35]. By Fostering a climate of research amongst undergraduates, could be important for recruiting $\mathrm{BOH}$ graduates as academics and encouraging more to consider enrolling in honours programs or other postgraduate study. The majority of students in this study indicated that they would prefer to undertake post graduate studies as a fulltime load, therefore it is important that funding opportunities be available for those wishing to do so. For example, cost and concerns about personal funding have been reported as key perceived barriers for dental hygienists to undertake graduate education and finding time to combine study and work [35]. It is also possible that at the time students in this study completed the survey, many were still anticipating being offered a place in a dentistry program at a later stage. The growing number of males entering the oral health workforce, and having the opportunity now to 'upskill' (e.g. providing restorative services to adults of all ages), may lead to more OHTs setting up private practices, and working according to the Scope of Practice Standards. This model may help in providing alternative access to dental services for low income earners, and children, for example. More males entering the profession may see a shift in workplace preferences in the future, resulting in more OHTs working in areas of special needs (e.g. in prisons, or with patients with psychological, cognitive and physical disabilities); as is occurring in the nursing profession [21]

In order to assist $\mathrm{BOH}$ graduates in their desire to undertake further study, it is important that dental schools foster a climate where future career aspirations can become a reality for those who desire it [36]. By ensuring that new graduates are well equipped with the confidence to upgrade skills necessary for research and by seeking role models within the profession, the likelihood of broadening the scope of professional opportunities for OHTs may increase.

This study was strengthened by the high participation rate which allowed meaningful conclusions being drawn from this sample. Whilst the reliability of self-reported questionnaires for data collection has its limitations, this survey was carried out at the same time in the academic program for each cohort and the wording of the questions remained unchanged.

Further research is necessary such as repeating the survey for second and third year students to monitor whether stated career intentions changed over the three years of the program.

\section{Conclusions}

This study adds to the body of knowledge of the profile of $\mathrm{BOH}$ undergraduates and shows an increase in the number of males entering the profession over the ten year period. Job security, self-employment opportunities and the important nature of the work were key motivators for their career decision as well as being greatly influenced by a dentist. There appeared to be a general tendency for graduates to initially want to work in the public sector and then in the private sector five years after graduation. The proportion of those wanting an academic or research career remained unchanged over this time. It is important to continue to monitor these perceptions of how students, in the early stages of the $\mathrm{BOH}$ program, view themselves as graduates because any potential disproportion of public and private sector practitioners could affect oral health outcomes of the populations they intend to serve.

\section{Conflict of interest}

The authors declare that they have no competing interests associated with this study.

\section{References}

1. Gardner SP, Roberts-Thomson KF (2012) Predicting high achievers in the University of Adelaide, Australia, Bachelor of Oral Health program, 2002-09. J Dent Educ 76: 1646-1656. [Crossref]

2. Wallace LG, Cockrell DJ, Taylor JA (2010) The University of Newcastle's first cohor of Bachelor of Oral Health students: a social profile. Aust Dent J 55: 436-440. [Crossref] 
3. Moffat S, Coates D (2011) Attitudes of New Zealand dentists, dental specialists and dental students towards employing dual-trained Oral Health graduates. Br Dent J 211: E16. [Crossref]

4. Mariño RJ, Barrow SL, Morgan MV (2014) Australian/New Zealand Bachelor of Oral Health students: sociodemographics and career decisions. Eur J Dent Educ 18: 180186. [Crossref]

5. Kempster C, Luzzi L, Roberts-Thomson K (2015) Australian dentists: characteristics of those who employ or are willing to employ oral health therapists. Aust Dent $J 60$ : 154-162.

6. Teusner DN, Amarasena N, Satur J, Chrisopoulos S, Brennan DS (2016) Applied scope of practice of oral health therapists, dental hygienists and dental therapists. Aust Dent $J$ 61: 342-349. [Crossref]

7. Dyer TA, Robinson PG (2016) The acceptability of care provided by dental auxiliaries: A systematic review. J Am Dent Assoc 147: 244-254. [Crossref]

8. Calache H, Hopcraft MS (2012) Provision of oral health care to adult patients by dental therapists without the prescription of a dentist. J Public Health Dent 72: 19-27. [Crossref]

9. Pang LC, Anderson VR, Moffat SM (2012) Initial University of Otago oral health graduates' employment pathways and preparedness for work. $N Z$ Dent $J$ 108: 83-88. [Crossref]

10. Gallagher JL, Wright DA (2003) General dental practitioners' knowledge of and attitudes towards the employment of dental therapists in general practice. $\mathrm{Br}$ Dent $J$ 194: 37-41. [Crossref]

11. Naidu R, Newton JT, Ayers K (2006) A comparison of career satisfaction amongst dental healthcare professionals across three health care systems: comparison of data from the United Kingdom, New Zealand and Trinidad \& Tobago. BMC Health Serv Res 6: 32. [Crossref]

12. Csikar JI, Bradley S, Williams SA, Godson JH, Rowbotham JS (2009) Dental therapy in the United Kingdom: part 4. Teamwork--is it working for dental therapists? $\mathrm{Br}$ Dent J 207: 529-536. [Crossref]

13. Health Workforce Australia (2014) Australia's Future Health Workforce - Oral Health - Detailed Report, Canberra, Department of Health.

14. Vigild M, Schwarz E (2001) Characteristics and study motivation of Danish dental students in a longitudinal perspective. Eur J Dent Educ 5: 127-133. [Crossref]

15. Marino RJ, Morgan MV, Winning TA, Thomson WM, Marshall RI, et al. (2006) Sociodemographic backgrounds and career decisions of Australian and New Zealand dental students. J Dent Educ 70: 169-178. [Crossref]

16. Stewart JF, Spencer AJ, Roberts-Thomson KF (2006) "Social profile changes of firstyear dentistry students in South Australia. J Dent Res 85.

17. Gardner SP, Roberts-Thomson KF (2014) The effect of a change in selection procedures on students' motivation to study dentistry. Aust Dent J 59: 2-8. [Crossref]

18. Gardner SP, Roberts-Thomson KF (2012) Predicting High Achievers in the University of Adelaide, Australia, Bachelor of Oral Health Program, 2002-09. J Dent Educ 76: 1646-1656.
19. Australian Bureau of Statistics (2012) Australian Standard Classification of Occupations (ASCO) Second edition 1997 ABS Cat. no. 1220. Canberra.

20. Australian Institute of Health and Welfare (AIHW) (2014) Dental Workforce 2012. Cat no. HWL 53. Canberra, AIHW.

21. Australian Bureau of Statistics (2013) Australian Social Trends Work. ABS Cat no. 4102. Canberra

22. Nash DA, Friedman JW, Mathu-Muju KR, Robinson PG, Satur J, et al. (2014) A review of the global literature on dental therapists. Community Dent Oral Epidemiol 42: 1-10. [Crossref]

23. Gardner SP, Roberts-Thomson KF (2009). J Dent Res 88.

24. McKenzie K, Schweitzer R (2001) Who succeeds at University? Factors predicting academic performance in first year Australian university students. Higher Research \& Development 20: 21-33.

25. Morris S (1992) What kind of people want to become dentists? General Dental Counci Recruitment Working Party survey of first year undergraduate dental students. Br Dent $J$ 173: 143-144. [Crossref]

26. Schofield D, Fletcher S, Fuller J, Birden H, Page S (2009) Where do students in the health professions want to work? Hum Resour Health 7: 74. [Crossref]

27. Australian Bureau of Statistics (2012a) Cultural Diversity in Australia Reflecting a nation: Stories from the 2011 census. ABS Cat. no 2071. Canberra.

28. Bai L (1998) Monetary reward versus the national ideological agenda: Career choice among Chinese university students. J Moral Educ 27: 525.

29. Dorsey ER, Jarjoura D, Rutecki GW (2005) The influence of controllable lifestyle and sex on the specialty choices of graduating U.S. medical students, 1996-2003. Acad Med 80: 791-796. [Crossref]

30. Newton D, Grayson MS, Thompson LF (2005) The Variable Influence of Lifestyle and Income on Medical Students' Career Speciality Choices: Data from Two U.S. Medical Schools. Acad Med 80: 809-814. [Crossref]

31. Kay EJ, O'Brien KD (2006) Academic dentistry--where is everybody? Br Dent $J 200$ : 73-74. [Crossref]

32. McNamara S (2007) Oral health researcher: a viable career option. J Can Dent Assoc 73: 225-228. [Crossref]

33. Howe N, Srauss W, Martson RJ (2000) Millennials Rising: The Next Generation. New York, USA, Vintage Books.

34. Hart KA (2006) Generations in the workplace: finding common ground. MLO Med Lab Obs 38: 26-27. [Crossref]

35. Boyd LD, Bailey A (2011) Dental hygienists' perceptions of barriers to graduate education. J Dent Educ 75: 1030-1037. [Crossref]

36. Moffat SM, Coates DE (2011) New Zealand's oral health students--education and workforce implications. $N Z$ Dent $J$ 107: 51-56. [Crossref]

Copyright: $(02017$ Gardner S. This is an open-access article distributed under the terms of the Creative Commons Attribution License, which permits unrestricted use, distribution, and reproduction in any medium, provided the original author and source are credited. 